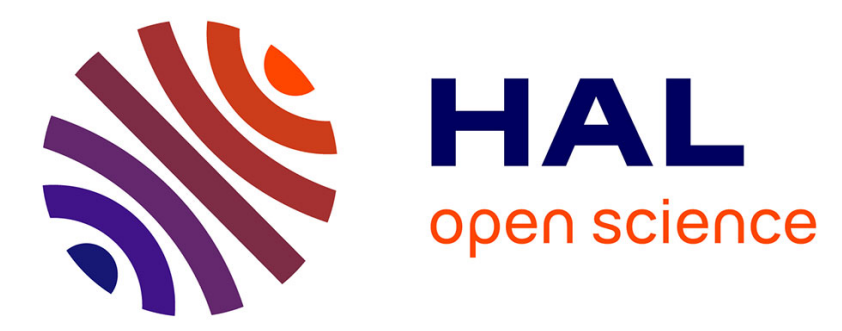

\title{
Ancient human bones studied and compared by near infrared spectroscopy, thermogravimetry and chemometrics
}

\author{
Alessandra Biancolillo, M. Tomassetti, R. Bucci, S. Izzo, F. Candilio, F. \\ Marini
}

\section{To cite this version:}

Alessandra Biancolillo, M. Tomassetti, R. Bucci, S. Izzo, F. Candilio, et al.. Ancient human bones studied and compared by near infrared spectroscopy, thermogravimetry and chemometrics. Journal of Near Infrared Spectroscopy, 2019, 27 (1), 10.1177/0967033518819417 . hal-02608318

\section{HAL Id: hal-02608318 \\ https://hal.inrae.fr/hal-02608318}

Submitted on 11 Jun 2021

HAL is a multi-disciplinary open access archive for the deposit and dissemination of scientific research documents, whether they are published or not. The documents may come from teaching and research institutions in France or abroad, or from public or private research centers.
L'archive ouverte pluridisciplinaire HAL, est destinée au dépôt et à la diffusion de documents scientifiques de niveau recherche, publiés ou non, émanant des établissements d'enseignement et de recherche français ou étrangers, des laboratoires publics ou privés. 


\title{
Ancient human bones studied and compared by near infrared spectroscopy, thermogravimetry and chemometrics
}

\author{
Alessandra Biancolillo ${ }^{1,2}$ (D), Mauro Tomassetti ${ }^{1}$, Remo Bucci ${ }^{1}$, \\ Simona Izzo $^{1}$, Francesca Candilio ${ }^{3}$ and Federico Marini ${ }^{1}$
}

\begin{abstract}
Near infrared spectroscopy and thermogravimetry have been coupled with chemometric exploratory methods in order to investigate ancient (pre-Roman/Roman) human bones from two different necropolises in Central-South Italy (Cavo degli Zucchi and Elea Velia). These findings have been investigated by principal component analysis and they have also been compared with ancient human bones from two Sudanese necropolises (Saggai and Geili). Samples coming from African and European necropolises, mainly differ in two aspects: the burial procedures and their historical period. The ritual applied in the European region involved cremation, while the one applied in the African necropolises did not. Bones from Italian sites (Cavo degli Zucchi and Elea Velia) are Pre-Roman/Roman while the others (from middle Nile) come from the Prehistoric, Meroitic, and Christian Sudanese age. Near infrared spectroscopy and thermogravimetric measures have been analysed either individually or by a mid-level data-fusion approach. Principal component analysis of the near infrared spectroscopy data allowed differentiation between burnt and unburnt samples, while from the scores plots extracted from the principal component analysis model based on the entire derived thermograms, it was possible to recognize the different clusters related to the various dating of samples. The data-fusion analysis led to considerations similar to those obtained from the model based on thermogravimetry data. Finally, instead of inspecting the entire thermogravimetry curves, principal component analysis was carried out on carbonates, total collagen and water losses only. In this case, the data-fusion approach has led to extremely interesting results; in fact, this model clearly shows that samples group in separate clusters in agreement with their age and the different burial rituals.
\end{abstract}

\section{Keywords}

Human bones, dating, thermogravimetry, near infrared spectroscopy, principal component analysis, data-fusion

Received 7 August 2018; accepted 25 November 2018

\section{Introduction}

The determination of the age of ancient human bones is important because it allows the characterization of objects found in tombs and it can be coupled with palaeontological information in order to disclose more about ancient populations. ${ }^{1}$ Various dating methodologies for bones have been reported in literature; classical methods use the carbon isotopes, ${ }^{2-6}$ but this approach presents some issues which could make the results not completely reliable ${ }^{5}$ and their accuracy is still under debate $;^{5,7}$ consequently, some alternatives had been proposed, such as those based on electron spin resonance ${ }^{8}$ or on the racemization of isoleucine. ${ }^{9}$ In recent years, some other dating approaches (involving different analytical techniques) have been published. For instance, two recent examples can be found in Liritzis and Laskaris ${ }^{10}$ and Marom et al., ${ }^{11}$ where the obsidian hydration phenomenon, ${ }^{10}$ or the single amino acid radiocarbon dating ${ }^{11}$ has been used to define the age of remains. Considering recent works in this context, in addition to the two previously mentioned approaches, several involve thermogravimetry (TG); for instance, in Tomassetti et al., ${ }^{12}$ TG has been used to distinguish ancient human bones

\footnotetext{
${ }^{1}$ Department of Chemistry, University of Rome “La Sapienza”, Rome, Italy ${ }^{2}$ Irstea UMR ITAP, Montpellier, France

${ }^{3}$ Department of Environmental Biology, University of Rome “La Sapienza”, Rome, Italy
}

\section{Corresponding author:}

Alessandra Biancolillo, Facolta di Scienze Matematiche, Fisiche e Naturali, Universita degli Studi di Roma La Sapienza, Piazzale Aldo Moro 5, Roma 00185, Lazio, Italy.

Email: alessandra.biancolillo@uniroma1.it 
(thousands years before Christ) from some others from the Christian era, while in Villanueva et al., ${ }^{13}$ thermal analysis has been used to date bone remains. Nevertheless, despite providing satisfactory results, these approaches present two main drawbacks: they are destructive and relatively time-consuming. On the other hand, in literature, it is not easy to find studies where fast and non-destructive approaches, such as near infrared (NIR) spectroscopy, have been applied to characterize ancient human bones. For example, in Stathopoulou et al., ${ }^{14}$ mid-infrared and NIR spectroscopies have been combined with X-ray diffraction to study bone diagenesis. More generic applications can be found in Cascant et al., ${ }^{15}$ where NIR is used to study the effect of the environment on burned bones, or in Mkukuma et al., ${ }^{16}$ where NIR signals have been used in combination with TG to characterize different varieties of bones on the basis of organic material.

The latter approach (i.e. the application of NIR spectroscopy and thermal analysis) has been considered particularly interesting because the two methodologies do not need a long sample preparation, the amount of material destroyed by $\mathrm{TG}$ is negligible, and they are relatively cheap; additionally, NIR analysis is also very fast.

Consequently, it was considered relevant to apply these two techniques for a more specific characterization of ancient human bones. Therefore, in the present work, NIR and TG are combined with principal component analysis $\left(\mathrm{PCA}^{17-19}\right)$ in order to test whether it would be possible to use these approaches to inspect human bones remains.

More specifically, 12 burnt bones from two Italian necropolises (called "Cavo degli Zucchi" and "EleaVelia") have been analysed by NIR and TG analyses and compared with 12 samples of human bones coming from two Sudanese necropolis: Saggai and Geili (described in Tomassetti et al. ${ }^{20}$ ).

The principal aim of the present study was to test whether it would be possible to use NIR and TG combined with PCA in order to highlight possible differences/similarities among ancient human bones coming from different historical periods and/or among remains which had undergone diverse burial rituals (e.g. involving cremation or not). The Sudanese remains used for comparison suit this goal because they come from the Prehistoric, Meroitic and Christian age and none of them underwent cremation during the funeral ritual.

In order to do this, PCA has been carried out on both individual data blocks (NIR and TG) and then, two data-fusion approaches ${ }^{21}$ have been also tested; the results are discussed below. Finally, in the second part of the present paper, following a more traditional approach proposed by Szoor ${ }^{22}$ (despite in his original work $^{22}$ chemometrics was not involved), the total carbonate and the total collagen mass losses ratios have been calculated and they have been used for the creation of additional PCA models. ${ }^{20,23,24}$

\section{Materials and methods}

\section{Data-fusion}

Data-fusion allows the joint analysis of data obtained from different analytical techniques. In particular, in the first part of the present work, low and mid-level data-fusion approaches have been carried out to combine the entire thermograms and NIR signals. In order to pursue the low level data-fusion, the PCA model has been calculated on the matrix obtained by concatenation of the original instrumental signals after blocknormalization. On the other hand, the mid-level datafusion was applied directly on the features extracted from the blocks. In particular, the principal components (PCs) obtained from the PCA models calculated on the individual data blocks have been concatenated and a further PCA model has been computed on the resulting matrix. ${ }^{21}$

Finally, in the second part of the work, NIR spectra have been merged with the three main TG mass losses and a low-level data-fusion approach ${ }^{21}$ has been carried out for the exploratory analysis. As mentioned above, the mid-level data-fusion has been applied by calculation of the PCA model on the super-scores (obtained by the concatenation of PCs extracted by models computed on individual data blocks).

\section{Samples}

The 12 bone samples analysed by NIR and TG come from skeletons unburied from Cavo degli Zucchi and Elea Velia (Italy) and they are estimated (by paleontologists) to date back to the Roman or Pre-Roman period (approximately from $300 \mathrm{BC}$ to $200 \mathrm{AD}$ ). All the human remains unearthed in that area underwent cremation during the funeral ritual and all the 12 samples show clear signs of burning.

At the time of the analysis, all samples appeared clean and they did not show the presence of ground soil on the surfaces.

NIR and TG signals collected during a previous work $^{20}$ have been used for comparison: these measures had been collected on samples unburied from two Sudanese necropolises (Saggai and Geili), the former dating back to the Neolithic (Prehistoric) age (7000$6000 \mathrm{BC}$ ), while the latter having been used through the Meroitic (ca. 300 BC-500 AD) and Christian (from $\sim 1000$ AD onwards) ages; none of them underwent cremation.

All samples (both the Italian and the Sudanese ones) have been analysed by the same NIR spectrometer and thermobalance.

\section{NIR spectra collection}

NIR analysis was carried out on a Thermo Nicolet FTNIR 6700 spectrometer, equipped with an integrating sphere and an InGaAs detector (Thermo Scientific, Walton, MA). The spectra were acquired at a nominal 
resolution of $4 \mathrm{~cm}^{-1}$ in the range $4000-10,000 \mathrm{~cm}^{-1}$, with 82 scans per spectrum. The samples were measured in four replicates, changing the side and the orientation of each sample on the sphere window. Prior to the chemometric analysis, replicates have been averaged.

\section{Thermal analysis}

Thermal analysis was carried out on a Thermoscale Perkin Elmer Sistem 7/4 equipped with a P.E. 3700 Data Station (PerkinElmer, Walthem, MA). Prior to the analysis, the samples were coarsely ground, in order to avoid the heat released during the grinding process altering them. Thermal analysis has been conducted under flux of oxygen $\left(\mathrm{O}_{2}\right)$ in the thermic range between $30^{\circ} \mathrm{C}$ and $850^{\circ} \mathrm{C}$ (heating rate $10^{\circ} \mathrm{C} / \mathrm{min}$ ).

\section{Results and discussion}

The 24 samples of ancient bones have been analysed by NIR spectroscopy and TG; signals have been collected and exported to Matlab (2015a - The Mathworks, Natick, MA) to perform data analysis using in-house routines or the PLS Toolbox v. 7.02 (Eigenvector Research, Wenatchee, WA). The thermograms are displayed in Figure 1(a), derived thermogram (DTG) in Figure 1(c), and NIR spectra in Figure 1(b).

Initially, different pretreatments have been tested on TG signals (mean centring alone or combined with 1st derivative or 2nd derivative, following the SavitzkyGolay algorithm ${ }^{25}$ ) prior to the creation of PCA models. The preprocessing approach and the number of the PCs to be extracted from data have been defined by inspection of the amount of the explained variance and of the root-mean-square error in cross-validation ( 5 cancellation groups). The 1st derivative ( 2 nd order polynomial, 15 points window) appeared to be the most suitable preprocessing approach. Consequently, the pretreated thermograms (i.e. the entire DTG curves) were analysed by PCA. The PCA model calculated on DTG signals involves four PCs which explain $97.68 \%$ of the total variance.

Figure 2(a) shows the scores of the different samples for the first two PCs. Samples show grouping tendencies according to their historical period. In fact, prehistorical samples (red diamonds in Figure 2(a)) have negative values for PC1, Meroitic and Christian samples are close to 0 (green squares and blue diamonds in Figure 2(a)) and (Pre-)Romans show positive values of PC1 (black stars in Figure 2(a)). As expected, Meroitic and Christian samples, which belong to almost the same era, group together at the same values of PC1. In Figure 2(b), PCA-loadings are displayed: from the figure it is quite evident that the mass losses which takes place between $650^{\circ} \mathrm{C}$ and $750^{\circ} \mathrm{C}$ (associable to carbonates), the one around $300^{\circ} \mathrm{C}$ (referable to collagen decomposition) and the evaporation of water (mass losses at temperatures lower than $100^{\circ} \mathrm{C}$ ) are strongly contributing to any component of the PCA model.

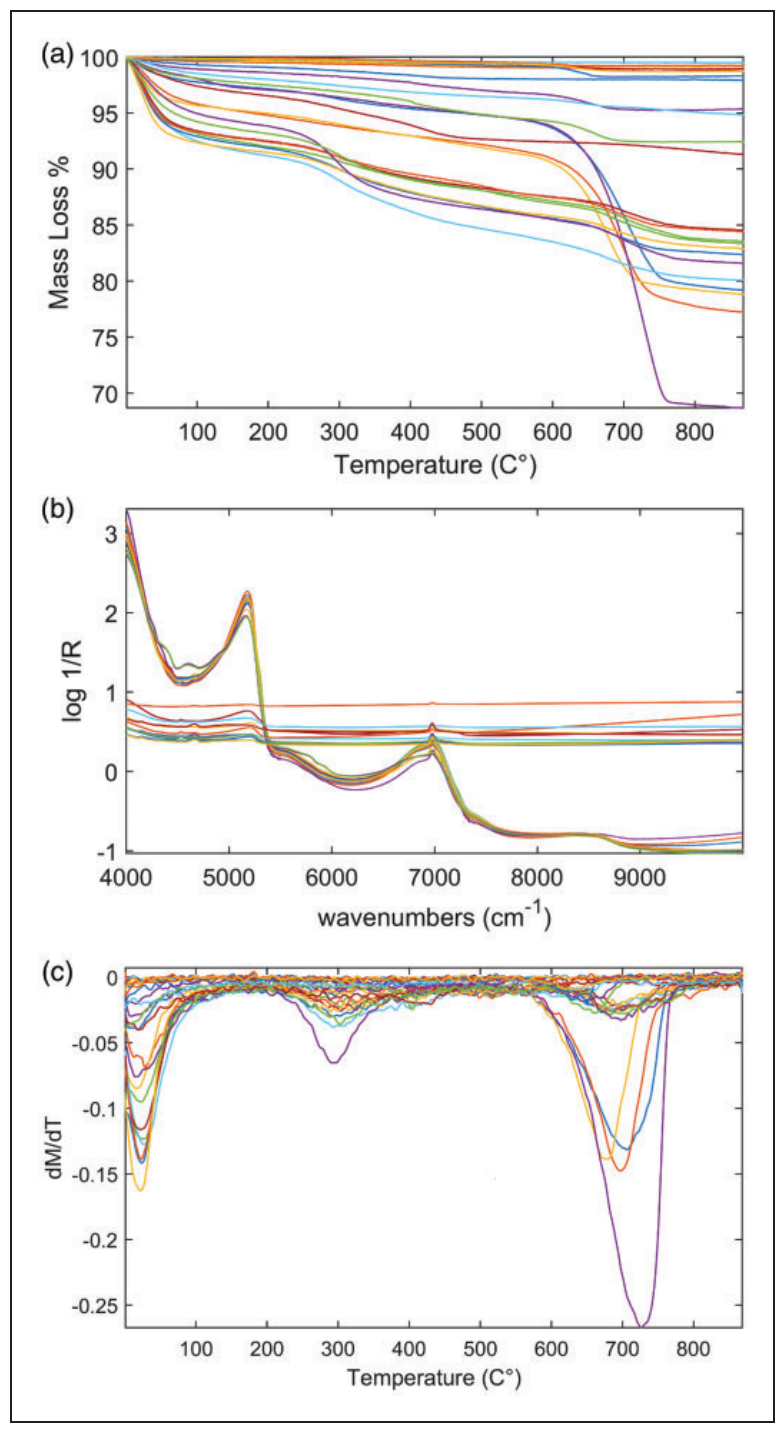

Figure 1. Instrumental signals: (a) thermograms (TG), (b) NIR spectra and (c) derived thermograms (DTG) of all the investigated samples.

Then, PCA analysis was been carried out for the NIR spectra. Spectroscopic signals have been pretreated by different preprocessing approaches (mean centring alone or combined with 1st derivative or 2 nd derivative $^{25}$ or standard normal variate ${ }^{26,27}$ ) prior to the creation of PCA models. In this case, the 1st derivative (2nd order polynomial, 15 points window) appeared the most appropriate pretreatment (pretreated NIR spectra are reported in Figure 3, in particular, in Figure 3(a) the remains from Italian necropolises are shown while in Figure 3(b) the findings from Sudanese necropolises are displayed). The best preprocessing approach and the number of PCs to be selected have been defined as mentioned describing the previous PCA model.

Differentiated NIR spectra (by 1st derivative) were analysed by PCA after further mean centring (2 PCs, explaining $98.07 \%$ of the total variance). Figure 2(c) shows the scores of the different samples onto the first two PCs. 



Figure 2. Scores and loading plots from PCA models. (a) Scores calculated on TG signals; (b) loadings calculated on TG signals; (c) scores calculated on NIR spectra; (d) loadings calculated on NIR spectra. Scores plots: (Pre)Roman - black stars; Prehistoric (Mesolithic) - red diamonds; Meroitic - green squares; Christian -blue squares. Loadings plots: continuous blue line - PC1; dashed orange line - PC2; dotted yellow line - PC3; dashed-dotted purple line - PC4.
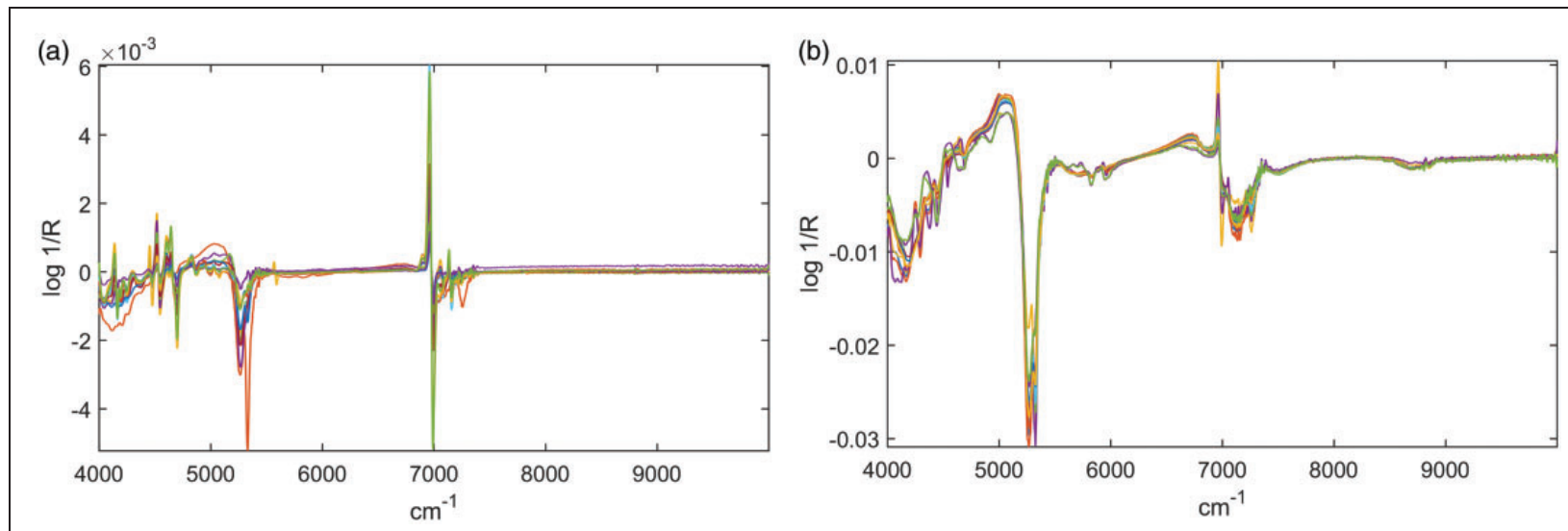

Figure 3. NIR spectra after first derivative: (a) remains from Italian necropolises; (b) findings from Sudanese necropolises.

Inspecting the scores plot, it is evident that PC1 allows distinguishing between burnt (black stars) and unburnt (red diamonds, green squares and blue triangles) bones, but the division according to the historical period observed when PCA is calculated on thermograms (Figure 2(a)) is no longer visible.

The loading plot for this model is reported in Figure 2(d). From the figure it is possible to detect which spectral variables are contributing the most to the model. Generally, both component 1 (continuous blue line) and component 2 (dashed orange line) present the main absorptions in the same ranges of the spectra: between 4000 and $5000 \mathrm{~cm}^{-1}$, attributable to stretching and bending of the $\mathrm{O}-\mathrm{H}$ combination bands in $\mathrm{Mg}-\mathrm{OH}$, two peaks around $5323 \mathrm{~cm}^{-1}$ and around $5271 \mathrm{~cm}^{-1}$, which can be associated to apatite absorption, ${ }^{16}$ and between 7000 and $7300 \mathrm{~cm}^{-1}$, which can be associated to 1st overtone of $\mathrm{Mg}-\mathrm{OH}$ stretching in dioctahedral layers and to the 1 st overtone of the $\mathrm{O}-\mathrm{H}$ stretch vibration in metal $-\mathrm{O}-\mathrm{H} .{ }^{16}$ Additionally, loadings from $\mathrm{PC} 2$ 
also show two peaks, one at $6964 \mathrm{~cm}^{-1}$ and one at $6991 \mathrm{~cm}^{-1}$ relatable to the 1 st overtone stretching vibrations of the $\mathrm{O}-\mathrm{H}$ group in hydroxyapatite. ${ }^{16}$

Finally, the low- and mid-level data-fusion approaches $^{21}$ have been tested, combining NIR spectra with the entire DTG signals. For the low level, pretreated TG and NIR signals have been merged and PCA was run on the resulting matrix. The model has been created extracting 2PCs, explaining $99.22 \%$ of the variance. The scores plot is extremely similar to the one shown in Figure 2(a), and it is therefore not reported. For what concerns the mid-level data-fusion, the components extracted from PCA models on the individual NIR and DTG data have been concatenated and a further PCA model has been calculated on these superscores. The latter model required four PCs, which explain $99.65 \%$ of the total variance. The resulting scores plot related to the data-fusion model is shown in Figure 4. The conclusions provided by this model are very similar to those exposed for the PCA calculated on first derivative thermogravimetric measurements.

In a second part of the work, a further (more traditional) approach, already applied in Szoor, ${ }^{22}$ based on the investigation of the main variables deducted from the TG curves (water, total collagen and carbonate mass losses) instead of using the entire TG signals, has been tested. This technique is used to estimate the age of archeological findings; e.g. Szoor ${ }^{22}$ has used the ratio between the sum of water and collagen mass losses and carbonate mass loss (water + collagen/carbonate) to date prehistoric animal bones.

The number and the origin of all samples investigated by us, together with their TG mass losses (\%), DTG peak temperatures $\left({ }^{\circ} \mathrm{C}\right)$, and $\mathrm{TG}$ residues are reported in Table 1.

In Figure 5(a), (b) and (c), a graphic representation as a bar plot of water, total collagen and carbonate losses are reported, respectively. In figures, blue bars represent mass losses for Sudanese (unburnt) samples, green ones are related to the burnt bones. On the $\mathrm{X}$-axis the number of samples is reported, following the same order used in Table 1.

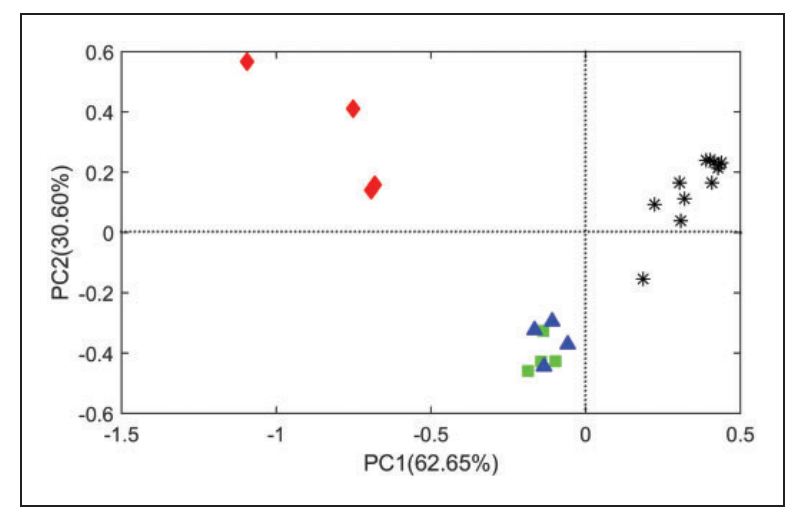

Figure 4. Mid-level data-fusion: scores plot. (Pre)Roman - black stars; Prehistoric (Mesolithic) - red diamonds; Meroitic - green squares; Christian - blue triangles.
From the bar plots, it is clear (and expected) that, despite a relevant variability, mass losses of the three main constituents (total carbonates, total collagen and water) are higher in unburnt samples than in burnt ones (differences have been tested by Tukey's test ${ }^{28}$ ).

Thus, PCA models have been calculated using only the three (mean-centred) main TG variables, i.e. water, total collagen and carbonate losses, as it has been done by Szoor $^{22}$ (despite chemometrics was not involved in his work) and in a previous work by our group. ${ }^{23,24}$ The scores plot from this PCA showed a clear separation among samples according to their age (consequently, also between burnt and unburnt samples) but this further model does not provide any additional information compared to the one calculated on the entire DTG curves, or by data-fusion and it is therefore not displayed here.

Additionally, a Low Level Data-Fusion model has been created, combining NIR data and the information about water, total collagen and carbonate mass losses. Data were mean-centred prior the creation of the model, which required two PCs; the scores plot is displayed in Figure 6(a). This shows the best grouping tendency among samples: burnt samples present negative values for $\mathrm{PC1}$, while the unburnt have positive score-values. Additionally, PC2 seems very suitable for dating samples: the oldest (Mesolithic) present positive values of PC2, burnt samples are close to zero values of PC2 and Meroitic and Christian samples present negative score-values for PC2.

Finally, also the mid-level data-fusion has been applied on this data. The scores obtained from the PCA model calculated on NIR spectra and those extracted from the bilinear decomposition of the main mass losses have been concatenated in a unique matrix and a further PCA model has been computed on the resulting data block. In this case, the first two PCs explained $100 \%$ of the variance: the scores plot is reported in Figure 6(b). Looking at the figure, it is possible to observe the results are definitely satisfactory and comparable to those shown in Figure 6(a); confirming the application of data-fusion on NIR and on the main mass losses is the most suitable approach to represent the data under study.

Finally, in order to have a deeper insight into data at study, the possibility of obtaining at least qualitative information about the cremation temperature of samples inquiring the TG curves has been investigated. In particular, the focus has been on which samples have been ignited at higher temperatures (around 600$800^{\circ} \mathrm{C}$ ) and which at lower ones (around $300-600^{\circ} \mathrm{C}$ ).

Looking at the bar plots reported in Figure 5, it is evident that the samples coming from Italian necropolises have been cremated (despite the process has not been completely successful for samples number 15 and, to a lesser extent, number 19) and those coming from Sudanese cites have not. In fact, in general, the first ones (from Elea Velia and Cavo degli Zucchi) show lower mass losses than the remains coming from Geili 


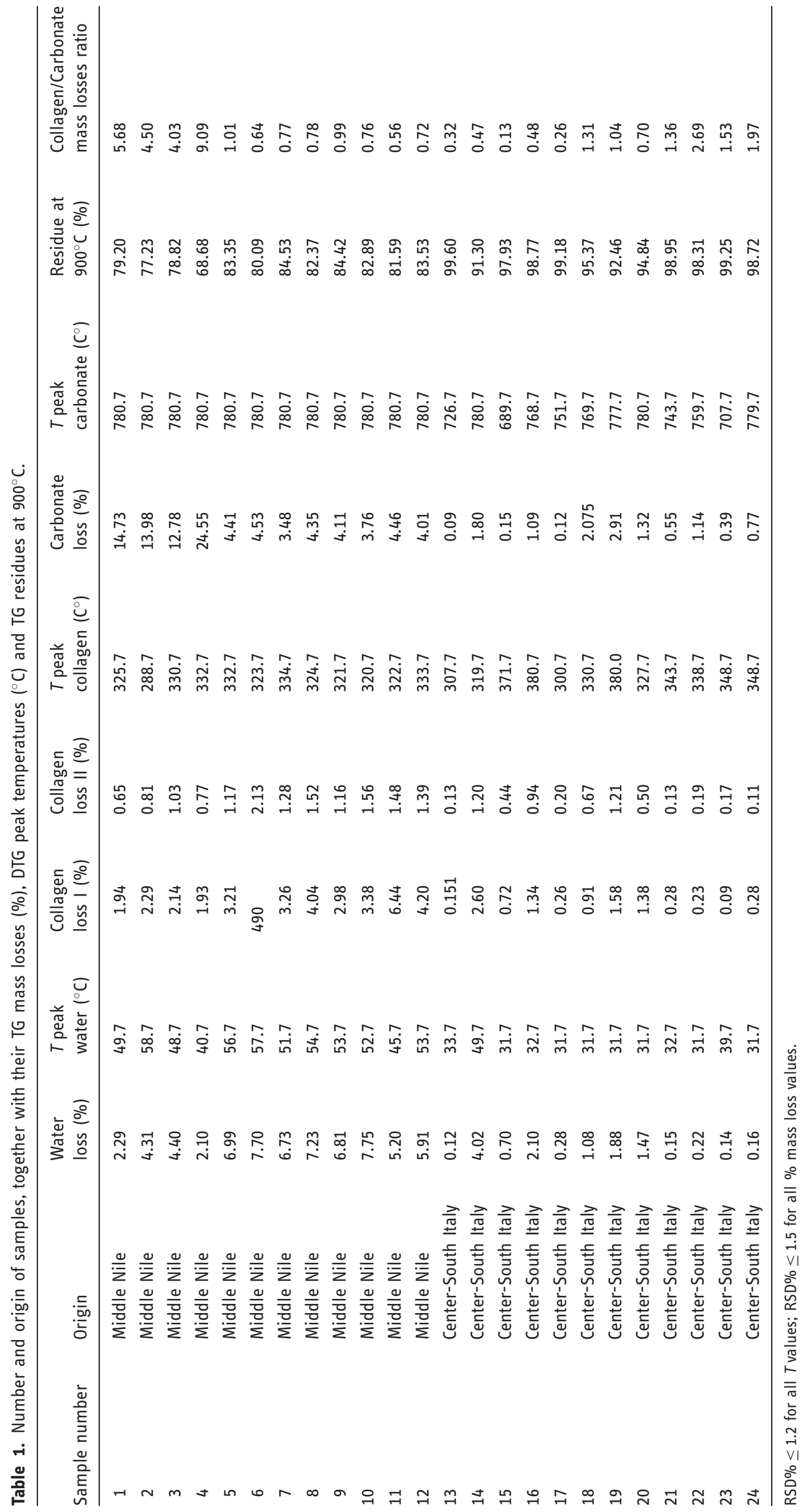




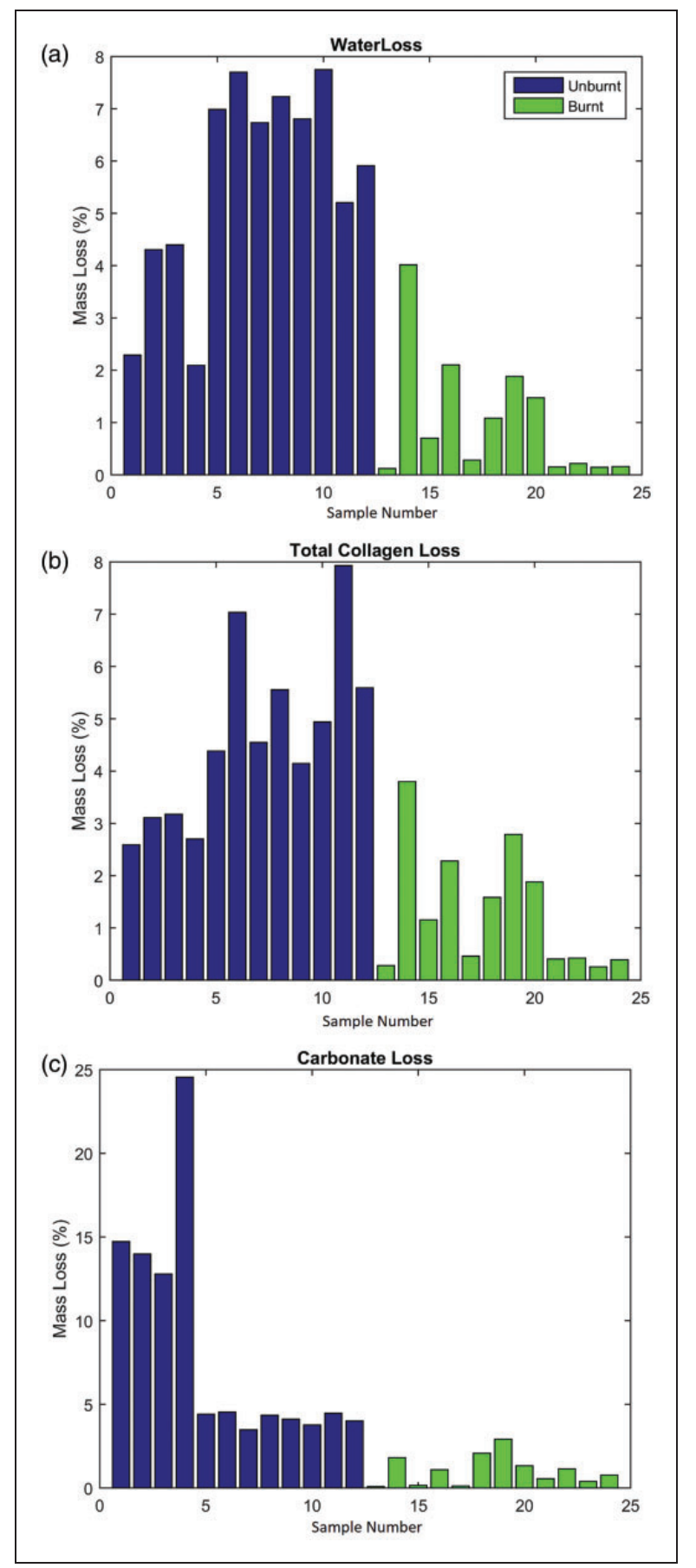

Figure 5. Percentages of mass loss vs. the number of sample. In blue unburnt samples (from sample 1 to sample 12), in green the burnt ones (from sample 13 to sample 24). (a) For water; (b) for collagen; (c) for carbonates.

and Saggai, suggesting that water, collagen and, in part, carbonate, have been lost during the cremation process. Moreover, some further information can be obtained considering the ratios between the total carbonate and the total collagen mass loss for burnt samples. In Figure 7, the values of these ratios, sorted in increasing order, are shown (the number displayed close to each diamond correspond to the numeration used in Table 1); looking at the figure it is possible to recognize a trend. Theoretically, samples having the lowest values
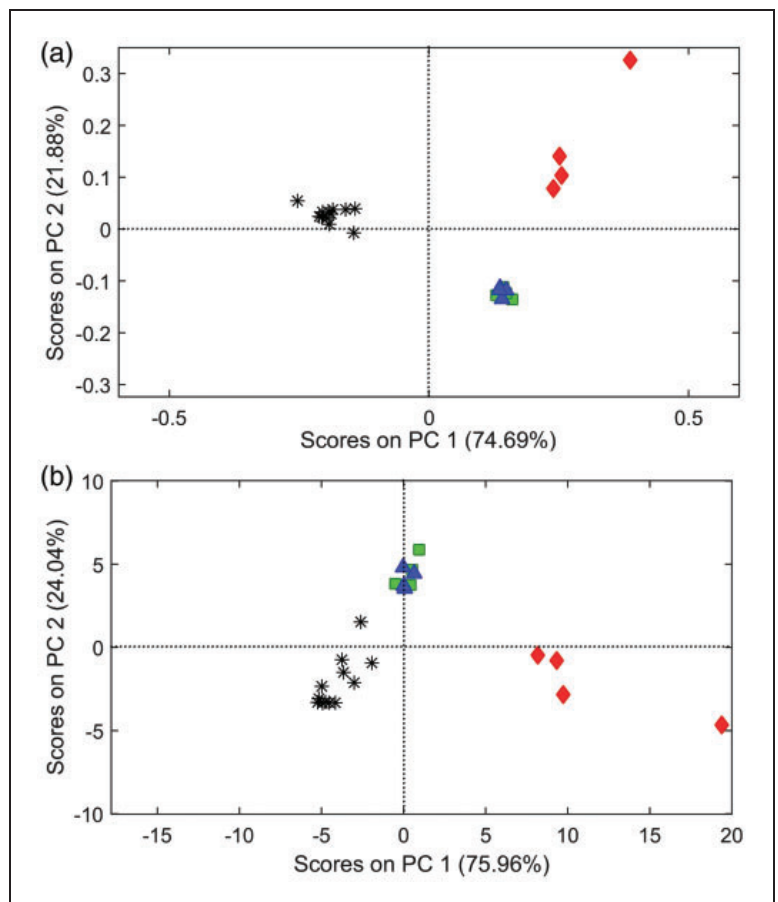

Figure 6. Scores plot. (a) Low-level data-fusion: PCA calculated on NIR spectra, water, total collagen and carbonate mass losses. (b) Mid-level data-fusion: PCA calculated on the matrix resulting from the concatenation of the scores extracted by PCA on NIR spectra and those extracted from the bilinear decomposition of the main mass losses. (Pre)Roman - black stars; Prehistoric (Mesolithic) red diamonds; Meroitic - green squares; Christian - blue triangles.

of the carbonate/collagen ratio (samples on the left side of the plot in Figure 7) are probably those burnt at lower temperatures (between $300^{\circ} \mathrm{C}$ and $600^{\circ} \mathrm{C}$ ) while those showing the highest values of it (on the right side of the figure) have been cremated at higher temperatures $\left(600-800^{\circ} \mathrm{C}\right)$. This assumption derives from the fact that the amount of collagen is expected to decompose almost completely at these higher temperatures, while carbonates only partially decompose. Such a consideration is strengthened by the fact that, usually, carbonates start to decompose at temperatures higher than $650^{\circ} \mathrm{C}$, i.e. when collagen is completely decomposed.

In agreement with the considerations exposed above, it would be even possible to sort samples in increasing order of the supposed cremating temperature from 15 to 22 , meaning that sample number 15 has been burnt at the lowest temperature and number 22 at the highest.

Please note that these suppositions would have been granted only if no other variables (except temperature) would have influenced the carbonate/collagen ratio. Nevertheless, it is demonstrated ${ }^{23,24}$ that aging of samples is one of the main factors altering the carbonate/ collagen ratio. Additionally, some authors have reported that even the bone type (i.e. the part of the skeleton it comes from) could affect the ratio, even if, according to Tomassetti et al. ${ }^{23}$ the effect that this could have on the value of the ratio is less relevant than the effect of the aging. Another factor that influences the composition of bones is the burial site where they 


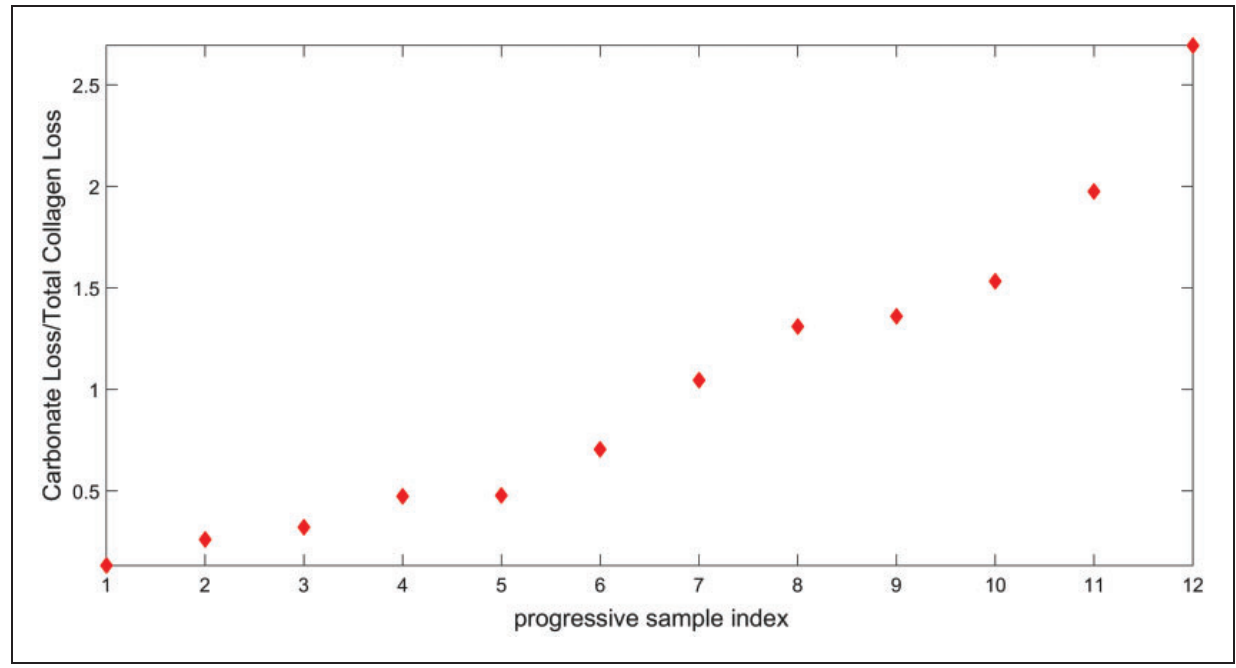

Figure 7. Plot of samples ordered according to increasing carbonate/collagen ratio. The number displayed close to each diamond represents the number of samples as reported in Table 1 . RSD\% $\leq 2.12$ for ratio values.

have been earthed; in fact, different soils and diverse humidity conditions would foster the re-precipitations of carbonates. Nevertheless, due to the fact that the remains at study in the present work come from only four necropolises, similar two by two, the effect of this latter factor should not be very relevant.

\section{Conclusions}

In the present paper, 12 ancient human bones unearthed from two different necropolises located in Italy have been investigated and compared with other 12 remains of human bones coming from two ancient Sudanese burial sites. Human findings have been analysed using different analytical techniques (i.e. NIR or thermal analysis) and chemometric approaches (PCA). The aim of the comparison was to test whether it would be possible to develop a suitable methodology for the investigation of these kinds of findings, in particular for distinguishing among human remains having different ages and/or which underwent different burial rituals.

It has been shown that both NIR and thermal analysis, combined with PCA, allow distinguishing samples coming from different necropolises and discerning among remains from various historical periods and differentiates between different burial rituals. Moreover, it has been shown that the investigation of the carbonate/ collagen ratios is a useful tool (combined with PCA) to investigate the ancient human bones.

Finally, the information obtained from the NIR analysis and the mass losses of the main compounds have been used in a joint mid- or low-level analysis. This has provided very promising results in highlighting grouping tendencies in data, representing the most appropriate methodology for the aim of the present paper.

\section{Declaration of conflicting interests}

The author(s) declared no potential conflicts of interest with respect to the research, authorship, and/or publication of this article.

\section{Funding}

The author(s) disclosed receipt of the following financial support for the research, authorship, and/or publication of this article: University of Rome "La Sapienza", the Center "Protezione dell'Ambiente e dei Beni Culturali-CIABC and the "Istituto per lo Studio dei Materiali Nanostrutturati" ISMN of CNR.

\section{ORCID ID}

Alessandra Biancolillo (D) http://orcid.org/0000-0002-94619597

\section{References}

1. Coppa A and Palmieri AM. Changing dietary patterns in El Geili. In: Caneva I (ed.) El Geili, the history of a middle Nile environment 7000 B.C.-A.D. 1500. Cambridge Monographs in African Archaeology 29. Oxford: BAR, 1988, pp.275-302.

2. Krueger HW and Sullivan CH. Models for carbon isotope fractionation between diet and bone. In: Turnland JF and Johnson PE (eds) Stable isotope in nutrition. Washington, DC: ACS, 1984, pp.205-222.

3. Lee-Thorp JA and van der Merwe NJ. Carbon isotope analysis of fossil bone apatite. S Afr J Sci 1987; 83: 71-74.

4. Lee-Thorp JA, Sealy JC and van der Merwe NJ. Stable carbon isotope ratio differences between bone collagen and bone apatite, and their relationship to diet. J Archaeol Sci 1989; 16: 585-599.

5. Saliège JF, Person A and Paris F. Preservation of $13 \mathrm{C} / 12 \mathrm{C}$ original ratio and $14 \mathrm{C}$ dating of the mineral fraction of human bones from Saharan tombs, Niger. J Archaeol Sci 1995; 22: 301-312.

6. Lanting J, Aerts-Bijma A and Van der Plicht J. Dating of cremated bones. Radiocarbon 2001; 43: 249-254.

7. Taylor RE. Radiocarbon dating of bone: to collagen and beyond. In: Taylor RE, Long A and Kra RS (eds) Radiocarbon after four decades. New York, NY: Springer, 1992, pp.375-402.

8. Ikeya $\mathrm{M}$ and Miki T. Electron spin resonance dating of animal and human bones. Science 1980; 29: 97-99. 
9. Bada JL. The dating of fossil bones using the racemization of isoleucine. Earth Planet Sci Lett 1972; 15: 223-231.

10. Liritzis I and Laskaris N. Fifty years of obsidian hydration dating in archaeology. J Non Cryst Solids 2011; 357: 211-219.

11. Marom A, McCullagh JSO, Higham TFG, et al. Single amino acid radiocarbon dating of Upper Paleolithic modem humans. Proc Natl Acad Sci U S A 2012; 109: 6878-6881.

12. Tomassetti M, Marini F, Bucci R, et al. A survey on innovative dating methods in archaeometry with focus on fossil bones. Trends Analyt Chem 2016; 79: 371-379.

13. Villanueva E, Girela F and Castellanos M. The application of differential thermal analysis and thermogravimetric analysis to dating bone remains. J Forensic Sci 1976; 21: 822-830.

14. Stathopoulou ET, Psycharis V, Chryssikos GD, et al. Bone diagenesis: new data from infrared spectroscopy and X-ray diffraction. Palaeogeogr Palaeoclimatol Palaeoeco 2008; 266: 168-174.

15. Cascant MM, Rubio S, Gallello G, et al. Burned bones forensic investigations employing near infrared spectroscopy. Vib Spectrosc 2007; 90: 21-30.

16. Mkukuma LD, SkakleI JMS, Gibson R, et al. Effect of the proportion of organic material in bone on thermal decomposition of bone mineral: an investigation of a variety of bones from different species using thermogravimetric analysis coupled to mass spectrometry, hightemperature $\mathrm{x}$-ray diffraction, and Fourier transform infrared spectroscopy. Calcified Tissue Int 2004; 75: 321-328.

17. Parson K. On lines and plans of closes fit to systems of points in space. Philos Mag 1901; 2: 559-572.

18. Wold S, Esbensen K and Geladi P. Principal component analysis. Chemometr Intell Lab Syst 1987; 2: 37-52.
19. Jolliffe IT. Principal component analysis. 2nd ed. New York, NY: Springer, 2002.

20. Tomassetti M, Marini F, Bucci R, et al. Comparison of NIR spectroscopy coupled o chemometrics and derivative thermogravimetry for relative dating of human fossil bones. J Therm Anal Calorim 2017; 130: 559-565.

21. Borràs E, Ferré J, Boqué R, et al. Data fusion methodologies for food and beverage authentication and quality assessment - a review. Anal Chim Acta 2015; 891: 1-14.

22. Szoor G. Fossil age determination by thermal analysis. $J$ Therm Anal 1982; 23: 83-91.

23. Tomassetti M, Marini F, Bucci R, et al. Human fossil bones: archaeometric classification using chemometrics and thermogravimetry. Influence of skeleton fossilization and its anatomical parts. Microchem $J$ 2016; 124: 396-401.

24. Tomassetti M, Marini F, Bucci R, et al. Archaeometric classification of ancient human fossil bones, with particular attention to their carbonate content, using chemometrics, thermogravimetry and ICP emission. Chem Cent $J$ 2014; 8: 26.

25. Savitzky A and Golay MJE. Smoothing and differentiation of data by simplified least squares procedures. Anal Chem 1964; 36: 1627-1639.

26. Barnes RJ, Dhanoa MS and Lister SJ. Standard normal variate transformation and de-trending of near-infrared diffuse reflectance spectra. Appl Spectrosc 1989; 43: 772-777.

27. Dhanoa M, Lister S, Sanderson R, et al. The link between multiplicative scatter correction (MSC) and standard normal variate (SNV) transformations of NIR spectra. J Near Infrared Spectrosc 1994; 2: 43-47.

28. Tukey J. Comparing individual means in the analysis of variance. Biometrics 1949; 5: 99-114. 